Research Article

\title{
Chronic Kidney Disease affecting the Characteristics of Blood Pressure: An Observational Study
}

\author{
Abhishek KB' ${\text { Sumanth } \text { BV }^{2} \text {, Ramesh B }}^{3}$ \\ ${ }^{1}$ Assistant Professor, Department of Emergency Medicine, Chamarajanagara Institute of Medical Science, Chamarajanagara, \\ Karnataka, India. \\ ${ }^{2}$ Associate Professor, ${ }^{3}$ Professor and HOD, Department of General Medicine, Chamarajanagara Institute of Medical Science, \\ Chamarajanagara, Karnataka, India.
}

DOI: https://doi.org/10.24321/2349.7181.202116

I $\quad \mathbf{N} \quad \mathbf{F} \quad \mathbf{O}$

Corresponding Author:

Sumanth BV, Department of General Medicine, Chamarajanagara Institute of Medical Science,

Chamarajanagara, Karnataka, India.

E-mail Id:

drsumanth.bv@gmail.com

Orcid Id:

https://orcid.org/0000-0002-0626-0861

How to cite this article:

Abhishek KB, Sumanth BV, Ramesh B. Chronic Kidney Disease affecting the Characteristics of Blood Pressure: An Observational Study. J Adv Res Med. 2021;8(3):22-26.

Date of Submission: 2021-12-09

Date of Acceptance: 2022-01-13
$\begin{array}{lllllllll}\mathbf{A} & \mathbf{B} & \mathbf{S} & \mathbf{T} & \mathbf{R} & \mathbf{A} & \mathbf{C} & \mathbf{T}\end{array}$

Background: Chronic kidney disease (CKD) is a global public-health problem that affects millions of individuals. Despite widespread use of medicines to slow the course of CKD, the burden of end-stage renal disease in many affluent nations remains high. Hypertension is far more frequent in persons with CKD than it is in the general population, and it becomes worse as renal function declines. Controlling blood pressure, which is a controllable risk factor for this complication, may reduce the risk of cardiovascular events and decrease the decline of renal function.

Objective: To asses the Characteristics of Blood Pressure in Chronic Kidney Disease.

Materials and Methods: A cross-sectional Study was conducted at MS Ramaiah Medical College, Bangalore from 1st of January 2018 to 31st of July 2019. A total of 100 Cases were included in the study.

Results: In our research, $10 \%$ of the participants were under the age of 30 . In the research, 33\% of the participants had Stage 3 CKD, 35\% had Stage 4 CKD, and 32\% had Stage 5 CKD. There was a significant difference in mean OSBP and mean ODBP with increasing CKD stage in the research. With rising CKD stage, mean OSBP and ODBP increased..

Conclusion: Ambulatory BP measurements revealed a significant degree of overestimation (white coat HTN) and underestimate (masked HTN) of BP among patients with CKD, indicating that adopting ABPM may assist avoid mistakes in BP measurement as well as correct treatment of HTN in CKD.

Keywords: Kidney Disease, Hypertension, Blood Pressure, Cardiovascular 


\section{Introduction}

Chronic kidney disease (CKD) is a world wide public-health problem that affects millions of individuals. Though use of medicines has become common to diminish the rate of progression of CKD, the burden of end-stage renal disease remains high in several developed countries. ${ }^{1,2}$ Hypertension is far more frequent in persons with CKD than it is in the general population, and it becomes worse as renal function declines. Excessive mechanical and oxidative stresses damage blood vessels in the kidney and other organs, potentially leading to renal failure and cardiovascular disease. ${ }^{3,4}$

Because hypertension is a preventable risk factor for this complication, lowering blood pressure may assist to reduce the risk of cardiovascular events and renal function loss. ${ }^{5,6}$ Hypertension is a major risk factor for the development of chronic kidney disease (CKD). Despite the fact that hypertension affects 86 percent of CKD patients, the number of people who can manage their blood pressure (BP) under $130 / 80 \mathrm{~mm} \mathrm{Hg}$ remains low. ${ }^{7}$ As the estimated glomerular filtration rate (eGFR) falls, patient health deteriorates, and 86 percent of patients will ultimately develop end-stage renal disease (ESRD). ${ }^{8,9}$ In CKD patients with and without proteinuria, rigorous control of blood pressure (BP) to $130 / 80$ and $140 / 90 \mathrm{mmHg}$, respectively, is recommended to decrease risks. ${ }^{10}$

However, a considerable percentage of CKD patients have poor blood pressure management, and the numbers vary across studies. ${ }^{11}$ Clinic blood pressure is judged insufficient to diagnose HTN and monitor overall BP management since it does not correlate well with ambulatory blood pressure monitoring (ABPM), which includes white-coat or masked Hypertension. Not only is CKD linked to an aberrant dipping pattern, but it's also linked to white-coat or disguised HTN. ${ }^{12}$

\section{Objectives}

To assess the characteristics of blood pressure in chronic kidney disease.

\section{Materials and Methods}

A cross-sectional study was conducted at MS Ramaiah Medical College, Bangalore, between 1st of January 2018 to 31st of July 2019.

Since it was a time bound study, a total of 100 patients with CKD included based on the inclusion and exclusion criteria.

The research covered all instances of chronic kidney disease identified in people over the age of 18 who were admitted to the hospital's Department of Medicine and Nephrology.

Patients with HIV, cirrhosis, transplant recipients, dialysis patients, and pregnant mothers were all excluded from the research.
The "KDIGO 2012 Clinical Practice Guideline for the Evaluation and Management of CKD" was used to select patients with chronic kidney disease (CKD). The history was gathered with a focus on CKD symptoms, $\mathrm{CHF}$, co-morbid conditions, and the length of time after CKD diagnosis and hemodialysis. Each participant had appropriate examinations performed on them, and the results were recorded. The Modification of Diet in Renal Disease (MDRD) approach was used to compute the eGFR, and CKD staging was conducted.

Each patient answered a short questionnaire at the time of the ABPM that captured information such as when they went to bed and when they woke up. Using the patient's diary, night-time was defined as actual sleep time.

As previously stated, ABPM was performed twice, first at the end of the drug-free baseline period and again at the end of the maintenance phase, using a Spacelabs model 90202 recorder. The monitor was configured to take data every 15 minutes during regular waking hours ( 6 a.m. to 10 p.m.), and every 30 minutes throughout the night (10 PM to 6 AM).

At least 6 readings were necessary for a suitable nighttime recording, whereas at least 30 readings were required for an acceptable daytime recording. The daytime parameters (BP and pulse rate) were calculated using the averages from $8 \mathrm{AM}$ to $8 \mathrm{PM}$, while the nocturnal parameters (BP and pulse rate) were calculated using the averages from midnight to $6 \mathrm{AM}$. The night/ day ratios for each metric were calculated. The systolic blood pressure (SBP) night/ day ratio was calculated and expressed as a percentage.

Patients were categorised into four dipping groups based on their baseline nocturnal BP fall: severe dippers, with a nocturnal BP fall of $20 \%$ or more; dippers, with a nocturnal BP fall of $10 \%$ to $20 \%$; non-dippers, with a nocturnal BP fall of $0 \%$ to $10 \%$; and risers, with a nocturnal increase in SBP. To investigate the effect of regression to the mean on changes in dipping status, we defined dipping status as the average of baseline and doxazosin BP.

\section{Statistical Analysis}

The data was imported into a Microsoft Excel spreadsheet and analysed using the SPSS 22 programme. Frequencies and percentages were used to represent categorical data. For qualitative data, the Chi-square test/ Pooled chi square was utilised as a test of significance. The mean and standard deviation were used to describe continuous data. When there are more than two groups in a variable, the ANOVA test is employed to determine its significance. The corelation test was used to see whether two continuous variables were related. Data visualisation: MS Excel and MS Word were used to create a variety of graphs, including bar diagrams, pie diagrams, and line diagrams. After applying all statistical 
principles, a $p$ value (probability that the result is true) of 0.05 was judged statistically significant.

\section{Results}

A total of 100 study subjects were included in the study and analyzed.

Table I.General Profile of CKD Subjects in the Study

\begin{tabular}{|c|c|c|c|}
\hline & & Count & $\%$ \\
\hline \multirow{3}{*}{ Age } & $<30$ years & 10 & $10 \%$ \\
\hline & 31 to 60 years & 65 & $65 \%$ \\
\hline & $>60$ years & 25 & $25 \%$ \\
\hline \multirow{2}{*}{ Gender } & Female & 29 & $29 \%$ \\
\hline & Male & 72 & $71 \%$ \\
\hline \multirow{2}{*}{$\begin{array}{c}\text { Type } 2 \text { Diabetes } \\
\text { Mellitus }\end{array}$} & No & 54 & $54 \%$ \\
\hline & Yes & 46 & $46 \%$ \\
\hline \multirow{4}{*}{$\begin{array}{c}\text { Number of } \\
\text { Antihypertensive } \\
\text { use }\end{array}$} & 1 & 15 & $15 \%$ \\
\hline & 2 & 30 & $30 \%$ \\
\hline & 3 & 40 & $40 \%$ \\
\hline & 4 & 15 & $15 \%$ \\
\hline \multirow{4}{*}{ Body Mass Index } & Underweight $(<18.5)$ & 3 & $3 \%$ \\
\hline & $\begin{array}{c}\text { Normal (18.5 to } \\
22.9)\end{array}$ & 27 & $27 \%$ \\
\hline & $\begin{array}{c}\text { Overweight (23 to } \\
24.9 \text { ) }\end{array}$ & 16 & $16 \%$ \\
\hline & Obese $(>25)$ & 54 & $54 \%$ \\
\hline \multirow{3}{*}{ Stages of CKD } & Stage 3 & 33 & $33 \%$ \\
\hline & Stage 4 & 35 & $35 \%$ \\
\hline & Stage 5 & 32 & $32 \%$ \\
\hline \multirow{3}{*}{ Proteinuria } & $2+$ & 21 & $21 \%$ \\
\hline & $3+$ & 53 & $53 \%$ \\
\hline & $4+$ & 26 & $26 \%$ \\
\hline
\end{tabular}

In our study, $10 \%$ were in the age group $<30$ years, $65 \%$ were in the age group 31 to 60 years and $25 \%$ were in the age group $>60$ years. Majority of them were males $71 \%$ and $29 \%$ were females. In the study $15 \%$ were on one anti hypertensive, $30 \%$ were on two anti-hypertensives, $40 \%$ were on three anti-hypertensive and $15 \%$ were on four anti hypertensives. In the study 33\% had Stage 3 CKD, 35\% had stage 4 CKD and 32\% had Stage 5 CKD. In the study $46 \%$ had Diabetes Mellitus and $54 \%$ did not have Diabetes Mellitus. In the study $21 \%$ had Proteinuria of $2+, 53 \%$ had Proteinuria of $3+, 26 \%$ had Proteinuria of $4+$.

In the study $27 \%$ were dippers, $7 \%$ were extreme dippers, $18 \%$ were risers and $48 \%$ were non-dippers. In our study,
$28 \%$ had controlled HTN, 29\% had masked HTN, 35\% had persistent HTN and $8 \%$ had white coat HTN.

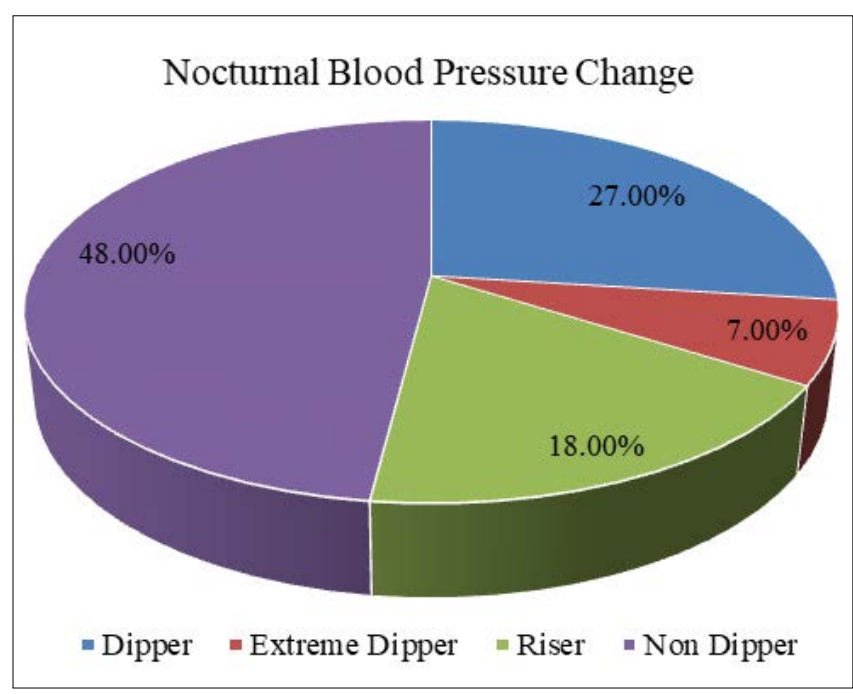

Figure I.Pie diagram showing Nocturnal Blood Pressure Changes distribution among CKD subjects

Table 2.Comparison of Mean Office Blood Pressure with Respect to Stage of CKD

\begin{tabular}{|c|c|c|c|c|c|}
\hline \multicolumn{2}{|c|}{ Mean } & \multicolumn{2}{c|}{ OSBP } & \multicolumn{2}{c|}{ ODBP } \\
\cline { 3 - 6 } \multicolumn{2}{|c|}{} & SD & Mean & SD & \\
\hline \multirow{3}{*}{$\begin{array}{c}\text { Stage of } \\
\text { CKD }\end{array}$} & Stage 3 & 135.2 & 14.81 & 77.5 & 7.12 \\
\cline { 2 - 6 } & Stage 4 & 138.7 & 12.83 & 77.5 & 7.24 \\
\cline { 2 - 6 } & Stage 5 & 147.9 & 12.77 & 82.7 & 6.45 \\
\hline \multicolumn{2}{|c|}{ P value } & \multicolumn{2}{|c|}{$0.001^{*}$} & \multicolumn{2}{c|}{$0.004^{*}$} \\
\hline
\end{tabular}

*ANOVA test.

In the study there was significant difference in mean OSBP and mean ODBP with increase in Stage of CKD. Mean OSBP and ODBP was increasing with increase in stage of CKD.

In the study, significant positive correlation was observed between stage of CKD and OSBP, ODBP, that is, with increase in stage of CKD there was increase in OSBP, ODBP, respectively, and vice versa.

Table 3.Spearman's Correlation between Stage of CKD and Blood Pressure

\begin{tabular}{|c|c|c|c|c|c|}
\hline \multicolumn{7}{|c|}{ Correlations } \\
\hline \multicolumn{2}{|c|}{} & $\begin{array}{c}\text { Stage } \\
\text { of CKD }\end{array}$ & OSBP & ODBP \\
\hline \multirow{2}{|c|}{$\begin{array}{c}\text { Spear- } \\
\text { man's } \\
\text { rho }\end{array}$} & $\begin{array}{c}\text { Stage } \\
\text { of } \\
\text { CKD }\end{array}$ & $\begin{array}{c}\text { Correlation } \\
\text { Coefficient }\end{array}$ & 1.000 & $0.346^{* *}$ & $0.209^{*}$ \\
\cline { 3 - 6 } & P value &. & $<0.001^{*}$ & $0.02^{*}$ \\
\cline { 2 - 6 } & $\mathrm{N}$ & 100 & 100 & 100 \\
\hline
\end{tabular}




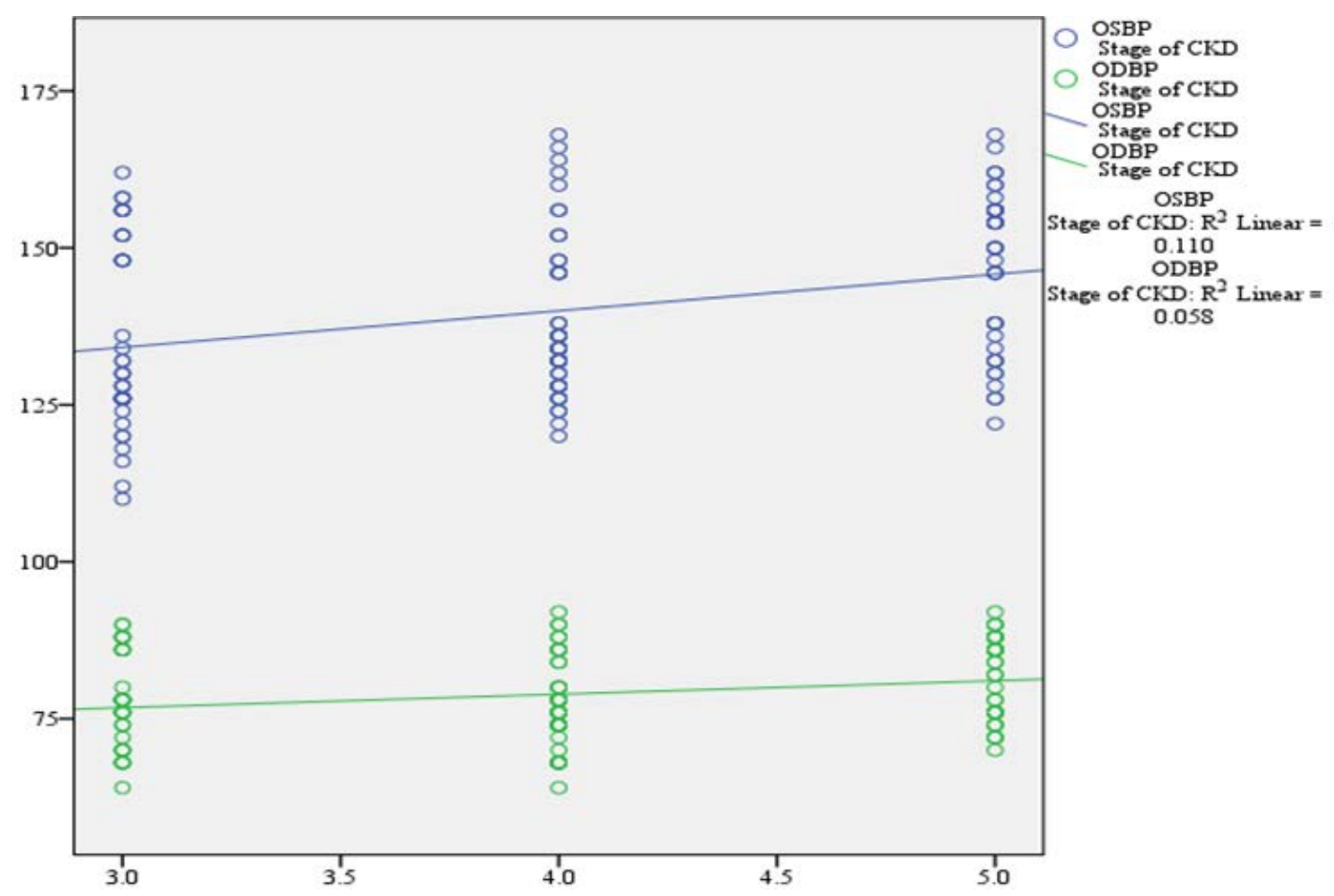

Figure 2.Scatter Plot Showing Correlation between Stage of CKD and Blood Pressure

\section{Discussion}

In our study, age of the patients varied from 18 to 80 years. The commonly affected age group in our study population was 31 to 60 years $(65 \%)$. The mean age of patients was $49.8 \pm 13.3$ years. In a study by Gorostidi et al. ${ }^{13}$ Cuncha C, ${ }^{14}$ mean age was $61 \pm 13.9,59 \pm 15$ years, respectively. In Prakash et al., ${ }^{15}$ study mean age was $47.5 \pm 14.9$ years and study by Singh et al., ${ }^{16}$ mean age was $45.22 \pm 15.2$ years. In our study, the sex ratio was $2.4: 1$; in study by limuro et a ${ }^{17}$ $(n=682[63.4 \%])$, Oh et al. ${ }^{18}(n=226[58.4 \%])$, Pogue et al. ${ }^{19}$ $(n=382[62 \%])$. Compared to other western studies, our study had little more prevalence of male patients.

In this study, 33\% had Stage 3 CKD, 35\% had Stage 4 CKD and $32 \%$ had Stage 5 CKD. In a study by Satoshi limuro al, ${ }^{17}$ it was $471(43.8 \%), 459(41.7 \%), 155(14.4 \%)$ in CKD Stage 3 , Stage 4 and Stage 5 respectively.

In our study, $46 \%$ had diabetes. In Satoshi limuro al ${ }^{17} 381$ (35.4\%) had diabetes. In Singh et al., ${ }^{16} 5094$ (31.6\%) out of 16120 had diabetes compared to other studies our study had little more prevalence of diabetes. In our study Diabetes was the main cause for CKD. In our study, $21 \%$ had proteinuria of $2+, 53 \%$ had proteinuria of $3+, 26 \%$ had proteinuria of $4+$. In limuro et al. ${ }^{17} 926(87 \%)$ had proteinuria.

In this study $27 \%$ were dippers, $7 \%$ were extreme dippers, $18 \%$ were risers and $48 \%$ were non-dippers. In limuro et al. ${ }^{17} 105$ ( 9.7\%) were extreme dipper, 395(36.7\%) were dipper, 408 (37.9\%) were non-dipper, 167 (15.5\%) were riser. In Otero et al. ${ }^{20} 4.7 \%, 47.2 \%, 42.3 \%, 5.9 \%$. In Pogue et al. ${ }^{9}$ dippers $19.7 \%$, non-dippers $41 \%$, reverse dippers $39.2 \%$. In Cha et al. dippers 33.3\%, non-dippers 34.5\%, reverse dippers or risers $17.3 \%$, extreme dippers $14.9 \%$. Since the study was conducted in a tertiary care centre, prevalence of advanced stage of CKD was more when compared to other studies and hence prevalence of non-dippers and risers was relatively more when compared to other studies. In our study, mean OSBP of stage $3,4,5$ is $135.2 \pm 14.81,138.7$ $\pm 12.83,147.9 \pm 12.77$ and mean ODBP $77.5 \pm 7.12,77.5 \pm$ $7.24,82.7 \pm 6.45$. In the study, significant positive correlation was observed between Stage of CKD and OSBP, ODBP; that is, with increase in stage of CKD, there was increase in OSBP, ODBP, respectively, and vice versa. In limuro et al. ${ }^{17}$ OSBP of stage $3,4,5$ was $129.7 \pm 17.2,132.7 \pm 17.8,137.8 \pm 18.8$ and mean ODBP $77.9 \pm 11.3,77.3 \pm 11.5,77.5 \pm 12.1$. Same pattern was also found in limuro et al. ${ }^{17}$

\section{Conclusion}

Our study showed that 24 hour ABPM provides a more reliable assessment of $B P$ in patients with CKD. Evaluation of ambulatory BP also showed a remarkable amount of overestimation (white coat HTN) and underestimation (masked HTN) of BP among patients with CKD so by using $A B P M$ we can circumvent errors in measurement of $B P$ and also helpful in proper management of HTN in CKD. We found that prevalence of persistent HTN was high in CKD population and increased in association with progression of CKD. Prevalence of non-dipping and risers are more in advanced stages of CKD. 


\section{Conflict of Interest: None}

\section{References}

1. Portaluppi F, Boari B, Manfredini R. Oxidative stress in essential hypertension. Curr Pharm Des. 2004;10:16951698. [PubMed] [Google Scholar]

2. Stenvinkel P. Chronic kidney disease: a public health priority and harbinger of premature cardiovascular disease. J Intern Med. 2010;268:456-467. [PubMed] [Google Scholar]

3. Drawz PE, Abdalla M, Rahman M. Blood pressure measurement: clinic, home, ambulatory, and beyond. Am J Kidney Dis. 2012; 60:449-462. [PubMed] [Google Scholar]

4. Coresh J, Selvin E, Stevens LA, Manzi J, Kusek JW, Eggers P, Van Lente F, Levey AS. Prevalence of chronic kidney disease in the United States. JAMA. 2007; 298:2038-47. [PubMed] [Google Scholar]

5. Sarafidis PA, Li S, Chen SC, Collins AJ, Brown WW, Klag MJ, Bakris GL. Hypertension awareness, treatment, and control in chronic kidney disease. Am J Med. 2008;121:332-340. [PubMed] [Google Scholar]

6. National Kidney Foundation. K/DOQI clinical practice guidelines for chronic kidney disease: evaluation, classification, and stratification. Am J Kidney Dis. 2002; 39:S1-S266. [PubMed]

7. Agarwal R, Nissenson AR, Battle D, Coyne DW, Trout $J R$, Warnock DG. Prevalence, treatment, and control of hypertension in chronic hemodialysis patients in the United States. Am J Med. 2003;115:291-297. [PubMed] [Google Scholar]

8. Gorostidi M, Sarafidis PA, de la Sierra A, Segura J, de la Cruz JJ, Banegas JR, Ruilope LM, Spanish AB. Spanish ABPM Registry Investigators. Differences between office and 24-hour blood pressure control in hypertensive patients with CKD: a 5,693-patient cross-sectional analysis from Spain. Am J Kidney Dis. 2013;62:285-94. [PubMed] [Google Scholar]

9. Pogue V, Rahman M, Lipkowitz M, Toto R, Miller E, Faulkner M, Rostand S, Hiremath L, Sika M, Kendrick C, Hu B, Greene T, Appel L, Phillips RA. African American Study of Kidney Disease and Hypertension Collaborative Research Group: disparate estimates of hypertension control from ambulatory and clinic blood pressure measurements in hypertensive kidney disease. Hypertension. 2009;53:20-27. [PubMed] [Google Scholar]

10. Sarafidis PA, Khosla N, Bakris GL. Antihypertensive therapy in the presence of proteinuria. Am J Kidney Dis. 2007;49:12-26. [PubMed] [Google Scholar]

11. Muntner P, Anderson A, Charleston J, Chen Z, Ford V, Makos G, O'Connor A, Perumal K, Rahman $M$, Steigerwalt $S$, Teal V. Hypertension awareness, treatment, and control in adults with CKD: results from the Chronic Renal Insufficiency Cohort (CRIC) Study. Am J Kidney Dis. 2010;55:441-51. [PubMed] [Google Scholar]

12. Kidney Disease Improving Global Outcome (KDIGO). KDIGO 2012 clinical practice guideline for the evaluation and management of chronic kidney disease. Kidney Int Suppl. 2013; 3: 1-150.

13. Gorostidi M, Sarafidis P, Sieraa A, Banegas J, De La Curz, Vinyoles E. Differences between office and 24 hrs blood pressure control in hypertensive patients with CKD: A 5693 patient cross sectional analysis from Spain. Am J Kid Dis. 2013;62(2):285-294. [PubMed] [Google Scholar]

14. Cunha C, Pereira S, Fernandes JC, Dias VP.. 24-hour ambulatory blood pressure monitoring in chronic kidney disease and its influence on treatment. Chinese General Practice. 2017;29(1):161-169. [Google Scholar]

15. Prakash S, Chibber SK, Prakash S, Pande DP, Joshi S, Gupta KK, Rana DS.Assessment of hypertension control in chronic kidney disease patients by ambulatory blood pressure monitoring. JAPI. 2005;53(1):769-74. [Google Scholar]

16. Singh AK, Farag YM, Mittal BV, Subramanian KK, Reddy SR, Acharya VN, Almeida AF, Channakeshavamurthy A, Ballal HS, Gaccione P, Issacs R. Epidemiology and risk factors of chronic kidney disease in India - results from the SEEK (screening and early evaluation of kidney disease) study. BMC Nephrol. 2013;14(1):114. [Google Scholar]

17. limuro S, Imai E, Watanabe T, Nitta K, Akizawa T, Matsuo $\mathrm{S}$, Makino H, Ohashi Y, Hishida A, Clinical Correlates of Ambulatory BP Monitoring among Patients with CKD. Clin J Am Soc Nephrol. 2013;8(5):721-730. [PubMed] [Google Scholar]

18. Oh YK, Chin HJ, Ahn SY, An JN, Lee JP, Lim CS, Oh KH. Discrepancies in clinic and Ambulatory Blood Pressure in Korean Chronic Kidney Disease Patients. Journal of Korean Medical Sciences. 2017;32(5):772-781. [PubMed] [Google Scholar]

19. Pogue V, Rahman M, Lipkowitz M, Toto R, Miller E, Faulkner M, Rostand S, Hiremath L, Sika M, Kendrick C, Hu B. Disparate estimates of hypertension control from ambulatory and clinic blood pressure measurements in hypertensive kidney disease. Hypertension. 2009;53(1):20-27. [PubMed] [Google Scholar]

20. Otero A, Dominguez Sardina $M$, Castineria $M$, Crespo J, Ferras A, Mojon A . Alteration of the Circadian Blood Pressure Pattern in Subjects with Chronic Kidney Disease: The HYGIA Project. J Hypertension. 2011;29:e174. [Google Scholar] 